\title{
Infective endocarditis related to the uncommon gram- negative pathogen Sphingobacterium spiritivorum
}

\author{
Hugo Abensur ${ }^{1}$, Felipe MB Dantas ${ }^{1}$, Maria RE Araujo ${ }^{2}$, Rodrigo N Campos ${ }^{3}$, Maria RT Araujo ${ }^{1}$ and Joao E Romao ${ }^{1 *}$ \\ ${ }^{1}$ CNT-Nephrology Clinic, Hospital BP Beneficencia Portuguesa de Sao Paulo, Sao Paulo, Brazil \\ ${ }^{2}$ Microbiology Service, Hospital BP Beneficencia Portuguesa de Sao Paulo, Sao Paulo, Brazil \\ ${ }^{3}$ Cardiology Service, Hospital BP Beneficência Portuguesa de Sao Paulo, Sao Paulo, Brazil
}

\section{Introduction}

The generous Sphingobacterium consists of non-fermenting gram-negative environmental bacilli that are rarely involved in human infections. The species Sphingobacterium multivorum and Sphingobacterium spiritivorum have occasionally been associated with chronic respiratory infections [1], bacteremia [2-4], cellulitis [5] and peritonitis [4] in patients with severe underlying conditions. Here we present the first reported case of a patient who experienced an infective endocarditis related to Sphingobacterium spiritivorum.

A 61-year-old man with past medical history of nephrotic syndrome and hypertension was admitted in another hospital with acute kidney injury. Blood tests revealed serum creatinine $2.5 \mathrm{mg} /$ $\mathrm{dL}$ and proteinuria $21.2 \mathrm{~g} / 24 \mathrm{~h}$. Ultrasonogram of kidneys and urinary tract was normal, and there was no evidence of calculi or hydronephrosis. A percutaneous kidney biopsy revealed focal segmental glomerulosclerosis. He was treated with prednisone $(80 \mathrm{mg} /$ day), spironolactone, losartan, atorvastatin, diuretics, and supportive treatments. Three weeks after first hospital discharge, the patient was readmitted in our nephrology service with an 8-day history of fatigue, mild mental confusion, drowsiness, asthenia, productive cough, and he denied fever and chills. Physical examination was remarkable only for crackles detected over the lower field of the right lung. Laboratory tests revealed serum creatinine $2.4 \mathrm{mg} / \mathrm{dL}$, urea $182 \mathrm{mg} / \mathrm{dL}$, sodium 139 $\mathrm{mmol} / \mathrm{L}$, and potassium $3.3 \mathrm{mmol} / \mathrm{L}$; his hemoglobin was $10.0 \mathrm{~g} / \mathrm{dL}$, white blood cell count $4,600 / \mathrm{uL}$ (neutrophils, $86 \%$; lymphocytes, $10 \%$; monocytes, $4 \%$ ), platelets $110 \times 10^{9} / \mathrm{L}$ C-reactive protein $458 \mathrm{mg} / \mathrm{dL}$, and serum albumin $1.4 \mathrm{~g} / \mathrm{dL}$. Urine dipstick was positive for blood $(++)$ and protein $(++++)$. Blood cultures were obtained, and he was started on empiric vancomycin and meropenem for concerns sepsis. The antibiotic was subsequently switched to intravenous oxacylin on day 5 , as Staphylococcus aureus (MSSA) grew in the two sets of blood cultures obtained at admission. A transthoracic echocardiogram revealed no remarkable findings. The patient made remarkable improvement without any new or recurrent problems. After two weeks, computed tomography of the chest showed large right pleural effusions and numerous cavitary infiltrates in both lungs. Sample of pleural fluid and two blood cultures were positive for gram-positive cocci, which were later identified as methicillin-sensitive Staphylococcus aureus (MSSA). At this time, a new holosystolic murmurs (grade $4 / 6$, heard best at the apex, and radiation to the carotids) was detected. The patient was hemodynamically stable, afebrile, and there were no skin or mucosal stigmata of endocarditis. Laboratory examination showed normocytic anemia (hemoglobin $10.3 \mathrm{~g} / \mathrm{dL}$ ), leukocytosis (total leukocyte count
$10,800 / \mathrm{uL}$ ) with neutrophilia (neutrophils $85 \%$ ), and C reactive protein of $289 \mathrm{mg} / \mathrm{L}$, and normal renal (serum creatinine $0.9 \mathrm{mg} / \mathrm{dL}$ ) and liver function tests. A transoesophageal echocardiography revealed mitral valve prolapse, and an image suggesting mitral valve vegetation with moderate to severe grade regurgitation, and chordal rupture. Antibiotic (oxacylin) was changed to vancomycin and meropenem. During the follow up, patient's clinical picture deteriorated, and pulmonary rales progressed up to upper lung levels. The patient was then taken to the operating room emergently where he had a mitral valve replacement. Intraoperative histopathological results of the mitral valve indicated marked acute inflammation, fibroinflammatory debris, and presence of Gram-negative rod. After two days of incubation of mitral valve debris, non-motile, oxidase positive, non-fermenting Gram-negative bacilli grew, identified as Sphingobacterium spiritivorum (Vitek 2, bioMérieux, Marcy-L'Etóile, France), and confirmed using the Vitek MS -MALDI-TOF (Matrix Assisted Laser Desorption Ionization Time of Flight, bioMérieux, Marcy-L'Etóile, France). Antimicrobial susceptibility testing was performed by automated microdilution broth method (Vitek 2). The results were reported as the minimal inhibitory concentration - MIC (CLSI Table 2B-5, M 100-S25-2015) [6], according to breakpoint criteria: ceftazidime (MIC $<4 \mu \mathrm{g} / \mathrm{mL}$ ), cefepime (MIC $<$ $4 \mu \mathrm{g} / \mathrm{mL})$, imipenem $(\mathrm{MIC}<0.5 \mu \mathrm{g} / \mathrm{mL})$, meropenem $(\mathrm{MIC} \leq 0.25 \mu \mathrm{g} /$ $\mathrm{mL}$ ), piperacillin/tazobactam (MIC $<8 \mu \mathrm{g} / \mathrm{mL}$ ), ciprofloxacin (MIC MIC $\leq 0.25 \mu \mathrm{g} / \mathrm{mL}$ ), and sulfamethoxazole/trimethoprim (MIV MIC $\leq 20 \mu \mathrm{g} / \mathrm{mL}$ ). Finally, like other flavobacteria-like organisms, it was highly resistant to colistin, amikacin and gentamicin. Piperacillin/ tazobactam was associated to antibiotic treatment. He had no fever and his clinical picture was improved. Five weeks after surgical intervention, a new transoesophageal echocardiography did not show any evidence of vegetation or abscess. However, after two weeks the patient condition deteriorated, with fever, and haemodynamic instability. Blood cultures grew Acinetobacter baumannii. On the $40^{\text {th }}$ day, the patient died of septic shock.

\section{Discussion}

We describe the first case of Sphingobacterium spiritivorum infective endocarditis in a native mitral valve with chordal rupture. Non-

*Correspondence to: Joao Egidio Romao, CNT-Nephrology Clinic, Hospital BP Beneficencia Portuguesa de Sao Paulo, Sao Paulo, Brazil, E-mail: joao.egidio@ uol.com.br

Received: August 06, 2019; Accepted: August 19, 2019; Published: August 21, 2019 
Table 1. Cases of Sphingobacterium spiritivorum as human pathogen reported worldwide

\begin{tabular}{|c|c|c|c|c|c|}
\hline & Marinella $^{7}$ & Tronel $^{8}$ & Koh $^{9}$ & Kämpfer ${ }^{10}$ & PR \\
\hline Year & 2002 & 2003 & 2013 & 2005 & 2016 \\
\hline Sex & M & M & F & F & M \\
\hline Age & 72 & 84 & 68 & 34 & 61 \\
\hline Predisposing condition & Parkinson disease & Refractory anemia & Leukemia chemotherapy & NA & nephrotic syndrome \\
\hline Symptoms & $\begin{array}{l}\text { Fever } \\
\text { Chills }\end{array}$ & $\begin{array}{l}\text { Leg rash } \\
\text { Fever }\end{array}$ & Fever & $\begin{array}{l}\text { Dry cough } \\
\text { Fever }\end{array}$ & $\begin{array}{l}\text { Cough, fever } \\
\text { Chills }\end{array}$ \\
\hline Diagnosis & $\begin{array}{l}\text { Cellulitis } \\
\text { Sepsis }\end{array}$ & $\begin{array}{l}\text { Cellulitis } \\
\text { Sepsis }\end{array}$ & Sepsis & Extrinsic allergic alveolitis & endocarditis \\
\hline Isolation & Blood & Blood & Blood & $\begin{array}{l}\text { Steam iron } \\
\text { Water reservoir }\end{array}$ & $\begin{array}{l}\text { Mitral valve } \\
\text { Infected debris }\end{array}$ \\
\hline Treatment & NA & $\begin{array}{l}\text { Amoxicillin-clavulanate } \\
10 \text { days }\end{array}$ & $\begin{array}{l}\text { Ciprofloxacin } \\
11 \text { days }\end{array}$ & NA & $\begin{array}{l}\text { Piperacillin-tazobactam } \\
21 \text { days }\end{array}$ \\
\hline Outcome & Recovered & Recovered & \begin{tabular}{|l} 
Died \\
$11^{\text {th }}$ day
\end{tabular} & Recovered & Died \\
\hline
\end{tabular}

M: male; F: female; NA: not available; PR: present report

fermenting gram-negative bacteria have been regarded historically as either environmental contaminants or organisms of low pathogenicity, and hence not clinically significant $[2,4,7]$. However, their emergence as significant causes of nosocomial bacteraemia has more recently been noted, particularly with regard to immunocompromised patients $[2,3,7]$. Sphingobacterium species, S. multivorum and S. spiritivorum, are non-fermenting, non-mobile, non-spore-forming aerobic gramnegative bacilli, and they are usually isolated from soil, water, and plant material.

S. spiritivorum has only been clearly incriminated as a human pathogen in four related cases worldwide. It was reported to cause of cellulitis and sepsis [8-10] or related to allergic reaction and hypersensitivity pneumonitis [11] (Table 1). In 2002, Marinella [8] first described the case of an elderly man with cellulitis and sepsis due to Sphingobacterium spiritivorum the patient most likely acquired from walking barefoot in his back yard. Tronel et al. [9] in 2003 reported a case of S. spiritivorum isolated from the blood cultures of an 84-yearold man with foot cellulitis. This bacterium was susceptible to most of the antibiotics tested, including glycopeptides, but was resistant to aminoglycosides and polymyxins; treatment with amoxicillinclavulanate cured the infection. In 2013, Koh et al. [10] reported a case of $S$. spiritivorum bacteremia in a 68-yr-old woman, who was diagnosed with acute myeloid leukemia and subsequently received chemotherapy. The patient received antibiotic therapy for 11 days but died of septic shock. In 2005, Kämpfer et al. [11] reported a case of extrinsic allergic alveolitis caused by $S$. spiritivorum from the water reservoir of a steam iron. Although human infection is rare, S. spiritivorum can be a fatal opportunistic pathogen in immunocompromised patients [10]. More recently, Gupta et al. [12] reported a case of an 80-year-old woman with end stage renal failure, with type 2 diabetes mellitus, was established on long term haemodialysis; she experienced symptoms of a generalized infection with no specific signs on examination to identify a potential source. A set of blood cultures from the dialysis line and haemodialysis circuit both grew gram negative rods from the aerobic bottle only. The microorganism was identified to be Sphingobacterium spiritivorum [12].

\section{Conclusion}

We present a case of infective endocarditis caused by S. spiritivorum. The infection involved a native mitral valve and it was complicated by chordal rupture. The patient recovered following mitral valve replacement, and specific antibiotic therapy. However, in the following weeks the patient developed sepsis and died. Only a few case reports of human infections caused by S. spiritivorum have been published. To our knowledge, this is the first reported case of infective endocarditis caused by $S$. spiritivorum. This bacterium was susceptible to most of the antibiotics tested, but was highly resistant to colistin, amikacin and gentamicin.

\section{References}

1. Reina J, Borrell N, Figuerola J (1992) Sphingobacterium multivorum isolated from a patient with cystic fibrosis. Eur J Clin Microbiol Infect Dis 11: 81-82. [Crossref]

2. Freney J, Hansen W, Ploton C, Meugnier H, Madier S, et al. (1987) Septicaemia caused by Sphingobacterium multivorum. J Clin Microbiol 25: 1126-1128. [Crossref]

3. Holmes B, Owen RJ, Hollis DG (1982) Flavobacterium spiritivorum, a new species isolated from human clinical specimens. Int J Syst Bacteriol 32: 157-165.

4. Holmes B, Owen RJ, Weaver RE (1981) Flavobacterium multivorum, a new specie isolated from human clinical specimens and previously known as group IIk biotype 2 . Int J Syst Bacteriol 31: 21-34

5. Nemoto D, Hitomi S, Moriyama Y, Iwamoto K, Saito K (2019) Cellulitis Complicated with Bacteremia Due to Sphingobacterium Species: A Report of Two Cases and a Literature Review. Intern Med 18: 2178. [Crossref]

6. Clinical and Laboratory Standards Institute (2015) Performance Standards for Antimicrobial Susceptibility Testing; Twenty-fifty Informational Supplement. CLSI document M100-S25. Wayne, PA.

7. Manfredi R, Nanetti A, Ferri M, Mastroianni A, Coronado AV, et al. (1999) Flavobacterium spp. organisms as opportunistic bacterial pathogens during advanced HIV disease. J Infect 39: 146-152. [Crossref]

8. Marinella MA (2002) Cellulitis and sepsis due to Sphingobacterium. JAMA 288: 1985 [Crossref]

9. Tronel H, Plesiat P, Ageron E, Grimont PA (2003) Bacteremia caused by a novel species of Sphingobacterium. Clin Microbiol Infect 9: 1242-1244. [Crossref]

10. Koh YR, Kim SY, Chang CL, Shin HJ, Kim KH, et al. (2013) The first Korean case of Sphingobacterium spiritivorum bacteremia in a patient with acute myeloid leukemia. Ann Lab Med 33: 283-287. [Crossref]

11. Kämpfer P, Engelhart S, Rolke M, Sennekamp J (2005) Extrinsic allergic alveolitis (hypersensitivity pneumonitis) caused by Sphingobacterium spiritivorum from the water reservoir of a steam iron. J Clin Microbiol 43: 4908-4910. [Crossref]

12. Gupta A, Logan J, Elhag N, Almond (2016) Sphingobacterium spiritivorum infection in a patient with end stage renal disease on haemodialysis. Ann Clin Microbiol Antimicrob 15: 25. [Crossref]

Copyright: (C2019 Abensur H. This is an open-access article distributed under the terms of the Creative Commons Attribution License, which permits unrestricted use, distribution, and reproduction in any medium, provided the original author and source are credited. 
